\title{
Parity and Short-Term Estradiol Treatment Utilizes Similar Cellular Mechanisms to Confer Protection Against Breast Cancer
}

\author{
Arunkumar Arumugam Ramadevi Subramani Sushmita Nandy Rebecca Lopez \\ Thiyagarajan Boopalan Rajkumar Lakshmanaswamy
}

Center of Excellence in Cancer Research, Department of Biomedical Sciences, Paul L. Foster School of Medicine, Texas Tech University Health Sciences Center, El Paso, TX, USA

\section{Key Words}

Breast cancer • Pregnancy - Short-term estrogen treatment $\cdot$ Cell survival $\cdot$ Apoptosis $\cdot$ Cell migration $\cdot$ JAK/STAT pathway

\begin{abstract}
Background: Protective effect of early pregnancy and short-term estrogen treatment (STET), against breast cancer is well established. The underlying mechanisms are not well understood. In this study, we compared the mammary gland cellular microenvironment influenced/ induced by parity and STET alongside age-matched controls. Methods: Parous, STET, and control rats were injected with N-methyl-N-nitrosourea at 15 weeks and monitored for the development of mammary cancer. A subset of 4 rats were killed five weeks post carcinogen treatment and mammary gland samples were isolated and subjected to molecular analysis. Results: Our results demonstrated a reduction in cell survival, extracellular matrix associated proliferation, hormonal and growth factor receptor pathways in the experimental groups compared to control rats. Moreover, concomitant reductions in the EMT markers along with cell migration regulators were also observed in parous and STET groups. Hormonal receptor such as GHR, PR, ER $\alpha$ and growth factor receptors IGFR, EGFR and erbB2 were down regulated in the treatment groups. Further analysis revealed that parity and STET drastically reduced the expression, activation of JAK2 and nuclear localization of STATs. Conclusion: Parity and STET by targeting major cell signaling pathways involved in cell survival, cell migration and cell death reduces the mammary tumor promoting environment.
\end{abstract}




\section{Introduction}

Early full term pregnancy in life is the only known natural phenomenon that reduces the risk of breast cancer [1-3]. This early pregnancy-induced protection against breast cancer is also well established in the rodent models [4-7]. Several investigations have been carried out to define the mechanism behind pregnancy-induced protection against breast cancer but the knowledge acquired from these studies are still limited.

Earlier studies have shown that parity causes change in the systemic environment that leads to reduction in prolactin (PRL), growth hormone (GH) and insulin like growth factors (IGFs), factors that promote mammary carcinogenesis [6, 8-11]. Differentiation of mammary glands due to pregnancy has also been attributed as a reason for parity-induced protection against mammary cancer [12]. Further, some studies have reported that mammary stem cells and altered gene expressions could play a role in lowered risk of mammary cancer in parous subjects $[13,14]$.

Earlier we and others have shown that administration of ovarian hormones estrogen and progesterone rendered the mammary gland resistant to tumorigenesis $[7,15,16]$. For the first time, we showed that short-term treatment with pregnancy levels of estradiol alone or in combination with progesterone conferred protection against MNU induced mammary cancer, mimicking the protective effect of parity [17]. Further, we have also demonstrated that short-term estradiol treatment (STET) was effective in reducing mammary cancer incidence in p53 null and MMTV/neu transgenic mouse models [18].

Even though parity and STET reduces breast cancer incidence, the molecular mechanism underlying this protective effect is not well understood. Several investigations on hormonal or parity-induced prevention of breast cancer emphasize the significance of promotional environment [19-21]. But there is a major void in identifying the key factors participating and/or influencing this phenomenon. The current study was undertaken to understand the molecular players that are responsible for conferring protection against mammary carcinogenesis due to parity and STET. To identify the molecular players that are unique for breast cancer protection, we compared the molecular events that happen in sequel due to parity and STET.

\section{Materials and Methods}

\section{Animals}

Five week old Sprague Dawley rats were purchased from Harlan Sprague Dawley (Indianapolis, IN and San Diego, CA). The rats were housed in a temperature-controlled room with a 12-h light and 12-h dark cycle. They were provided food (Teklad, Madison, WI) and water ad libitum. Seven week old female rats were mated with males of approximately the same age. The pups were separated immediately after parturition. Animals were used for carcinogenesis experiments six weeks after parturition to allow involution of the mammary glands. All procedures followed the Animal Care and Use Committee guidelines of Texas Tech University Health Sciences Center.

\section{Estradiol treatment}

Short-term estradiol (Sigma, St. Louis, MO) treatment was administered to animals from 7-9 weeks of age. Estradiol $(100 \mu \mathrm{g})$ was packed in individual silastic capsules (size $0.078 \mathrm{in}$. ID $\times 0.125 \mathrm{in}$. OD, $2 \mathrm{~cm}$ in length; Dow Corning, Midland, MI). Age matched controls and parous animals received empty silastic capsules. All silastic capsules were implanted dorsally and subcutaneously. The silastic capsules were primed before implantation by soaking in Medium 199 (GIBCO-Invitrogen, Carlsbad, CA) overnight at $37^{\circ} \mathrm{C}$.

\section{Carcinogen treatment}

A single intraperitoneal injection of MNU (Sigma, St. Louis, MO) at a dose of $50 \mathrm{mg} / \mathrm{kg}$ body weight was given to rats at the age of 15 weeks. MNU was dissolved in physiological saline that had been adjusted to $\mathrm{pH}$ 5.0. 
Mammary tumorigenesis

All groups (age-matched control, parous and STET; $n=20$ ) received MNU at 15 weeks of age. A subset $(n=4)$ of animals from each group were euthanized five weeks after the carcinogenic insult. Mammary glands from the rats were excised and a small portion was fixed in $10 \%$ neutral buffered formalin for histology and the remaining sample was snap-frozen in liquid nitrogen for molecular analysis. Mammary tumorigenesis in the remaining rats from each group was monitored by weekly palpation. The palpable mammary tumors were measured using a caliper. The two largest measurements of the tumor were recorded. The tumor volume was calculated using the formula $4 / 3 \pi \cdot r_{1}^{2} \cdot r_{2}$ where $r_{1}$ is the minor radius and $r_{2}$ is the major radius. Mammary tumors were surgically excised before they reached $2.0 \mathrm{~cm}$ in diameter and processed similarly like the mammary glands as described above.

\section{PCR array and real time RT-PCR}

The PCR array was performed as described previously [22]. In brief, rat mammary tissue samples were homogenized in Trizol reagent (Invitrogen, Carlsbad, CA) and $1 \mu \mathrm{g}$ of total RNA was used to perform PCR arrays to investigate PI3K signaling, AKT signaling, apoptotic signaling, cell migration and invasion signaling. (SABiosciences, Frederick, MD). A dissociation protocol run was conducted to test the melting temperature of the product as a confirmation for specificity of the primers. The $\Delta \Delta \mathrm{CT}$ method of relative quantification was used to determine the fold change in gene expression after normalization with panel of house keeping genes included in the array plate.

\section{Nuclear and cytoplasmic fractionation}

Nuclear and cytoplasmic fractions of the samples were prepared using NE-PER kit (Pierce Biotech, Rockford, IL) as per the manufacturer's directions. Briefly, normal mammary tissues (50mg) were homogenized with CER I buffer containing protease and phosphatase inhibitors. The homogenate was centrifuged and the supernatant was removed. The cell pellet was reconstituted with CER II buffer and vortexed vigorously for 15 seconds. It was then centrifuged at $16,000 \mathrm{x} g$ for 5 minutes and the supernatant was collected as the cytoplasic fraction. The nuclear fraction was extracted from the remaining pellet and both cytosolic and nuclear fractions were used for further analysis.

\section{Western blots}

Mammary tissue samples were homogenized with mammalian protein extraction buffer containing protease and phosphatase inhibitors (Roche Diagnostics, Indianapolis, IN). The homogenized lysates were centrifuged at $10,000 \mathrm{x}$ g for $20 \mathrm{~min}$ at $4^{\circ} \mathrm{C}$, and the supernatant fraction was collected. Protein concentrations were determined using the BCA protein assay kit (Pierce, Rockford, IL). Proteins were resolved on Mini-Protean TGX gels (Bio-Rad, Hercules, CA) and transferred to Immobilon-P polyvinylidene fluoride membranes (Millipore, Bedford, MA). The membranes were then incubated with indicated primary and specific secondary antibodies. The signal was developed using SuperSignal West Pico Chemiluminescent substrate detection solution (Pierce, Rockford, IL), and the membranes were stripped and reprobed with $\beta$-actin antibody (Sigma, St. Louis, MO). Primary antibodies used: pAKT, pmTOR, pp70S6K, pERK1/2, pp38, pJNK, cleaved caspase 3, pFAK, ILK, zeb1/2, vimentin, $\beta$-catenin, E-cadherin, slug, pEGFR, pIGFR, SHC1, GRB2, IRS1, pSTAT1, pSTAT3 from Cell Signaling (Boston, MA); Bcl2, Bax, Itg $\beta 4$, ER $\alpha$, ER $\beta$, PR and pSTAT5 from Santa Cruz Biotechnology (Santa Cruz, CA); GHR, histone H1 and perbB2 are from Abcam (Cambridge, MA); JAK2 and $\beta$-actin were from Sigma (St. Louis, MO). All the secondary antibodies used were obtained from Santa Cruz Biotechnology (Santa Cruz, CA).

\section{Gel shift assay}

Gel shift assay for STAT5 DNA binding activity was performed using Affymetrix EMSA Gel shift kit (Santa Clara, CA) as per the manufacturer's directions. Briefly, nuclear extracts were incubated for 30 minutes with labeled STAT5 DNA probe (chemiluminescent label), poly $\mathrm{d}(\mathrm{I}-\mathrm{C})$ and binding buffer. The transcription factor and DNA complex was then run on $6 \%$ non-denaturing polyacrylamide gel and transferred to Biodyne B nylon membrane (Pall Corporation, Covina, CA). The membrane was then blocked and incubated with streptavidin-HRP mixture and the signal was developed using the substrate solution. Nuclear extract provided in the kit was incubated with labeled STAT5 DNA probe was used as a positive control and cold probe was used as a negative control. 


\section{Immunohistochemistry}

Standard immunohistochemistry staining protocols were performed. In brief, specific antibodies were diluted in blocking buffer to a dilution of 1:100 - 1:400. Mammary tissue sections were deparaffinized and placed in three changes of xylene, then hydrated in graded alcohol series. Antigen retrieval was achieved by placing the slides in a decloaking chamber for 15 min and blocked with $1 \%$ fetal calf serum for 15 min. Primary antibody incubation was carried out for $1 \mathrm{~h}$ in a humidity chamber and then covered with Ultramarque Polyscan HRP (Cell Marque Corp. Rocklin, CA) for $30 \mathrm{~min}$. Then the tissue sections were incubated for 5 min with chromogen (3,3'-diaminobenzidine tetrahydrochloride [DAB]; DakoCytomation (Carpinteria, CA) and counterstained with modified Harris Hematoxylin (Sigma, St. Louis, MO) solution for $45 \mathrm{~s}$, washed and placed in bluing agent for 1 min and mounted. Mammary epithelial cells with brown staining were counted as positive regardless of the intensity of the staining, while those with bluish purple staining were counted as negative cells.

\section{Statistical analysis}

The differences between groups were analyzed by unpaired Student's $t$ test. Probability values $<0.05$ were considered to be statistically significant. The GraphPad Prism 5 software package version 5.03 was used to do all the statistical calculations.

\section{Results}

Parity and STET show similar effects on breast cancer incidence

It is well known that parity and mimicking pregnancy using short-term pregnancy levels of estrogen reduces carcinogen induced mammary cancer in rats [17]. In our current study we found that compared to young virgin rats $(100 \%)$, parous $(9.7 \%)$ and STET animals (6.4\%) had a remarkably reduced mammary cancer incidence (Fig. 1a). Moreover, the mammary tumor multiplicity was high in the young age matched virgin rats (4.8 tumors per rat) when compared to parous and estradiol treated rats (0.1 tumor per rat) (Fig. 1b). Similarly, parity and STET also increased the latency period for the appearance of palpable mammary tumor. The latency period was $225 \pm 41$ days (Mean \pm SEM) in parous, $214 \pm 39$ days in STET animals and $136 \pm 28$ in controls (136 \pm 28 ) (Fig. 1c).

\section{Parity and STET influenced early changes in gene expression}

To delineate the underlying mechanisms, we first compared the gene expression pattern of the mammary tissue of control and experimental groups using PCR microarray analysis. Our analysis identified several genes that are differentially regulated by parity and STET. Among the differentially regulated genes, we selected and sorted them according to their cellular function. Parity and STET had similar and variable effects on different gene expressions (Table 1$)$. Eif4B is highly down regulated $(-16.87$ fold) in the parity group among the genes involved in cell survival genes than that of virgin control, whereas estradiol treatment highly reduced the expression of gsk3b (-9.9 fold) (Table 1). The analysis also found that levels of other important regulators of survival such as Akt1, Pi3kca (PI3K catalytic sub unit), Srf, Foxg1 and Raf were down regulated by both parity and STET. Parity down regulated kcnh8 (Elk1) mRNA levels, which was not affected by STET (Table 1). The pro-apoptotic genes such as Casp9 and Foxo3 were up regulated in both the parous and STET groups, whereas anti apoptotic genes including Tlr4, Mtcp1, Tcl1a and Myd88 were reduced compared to the controls (Table 1). Cell migration is an important phenomenon, which determines the invasive capacity of the breast cancer cells. During cancer progression, cells have the tendency to overexpress genes involved in cell migration. In this study, parous rat mammary glands showed great reduction in the mRNA expression of cell motility genes Cdc42 (-12.87 fold), Rhoa ( -14.95 fold) and Irak1 ( -9.73 fold) when compared to virgin rat mammary glands. Short-term estradiol treatment highly reduced the expression of Itgb4 ( -9.5 fold), Irak1 ( -8.8 fold) and Hras ( -7.9 fold) (Table 1). Expressions of Igfr1 ( -7.6 and -6.8 ) as well as adaptors for growth factor receptor signaling Grb2 (-6.1 and -8.6), Grb10 (-5.2 and 
Fig. 1. Parity and STET drastically reduced mammary cancer incidence and growth. a) Mammary cancer incidence. Female Sprague Dawley rats were divided into 3 groups. V - age matched virgin control rats, $\mathrm{P}$ - parous rats and $\mathrm{E}$ - rats received $100 \mu \mathrm{g}$ of $17-\beta$-estradiol for 3 weeks (STET). Carcinogen (MNU;50 mg/kg) was administered at the age of 15 weeks as i.p. injection. Parous rats $(9.6 \%)$ and rats treated with estradiol (6.4\%) had a significant decrease in mammary cancer incidence compared to age matched virgins (100\%). b) Number of mammary tumors observed per rat. Parous and STET groups had a reduced mammary tumor burden. c) Tumor latency period. Significant increase in the tumor latency period was observed in experimental groups than control group, which demonstrates the effectiveness of parity and STET against breast cancer.

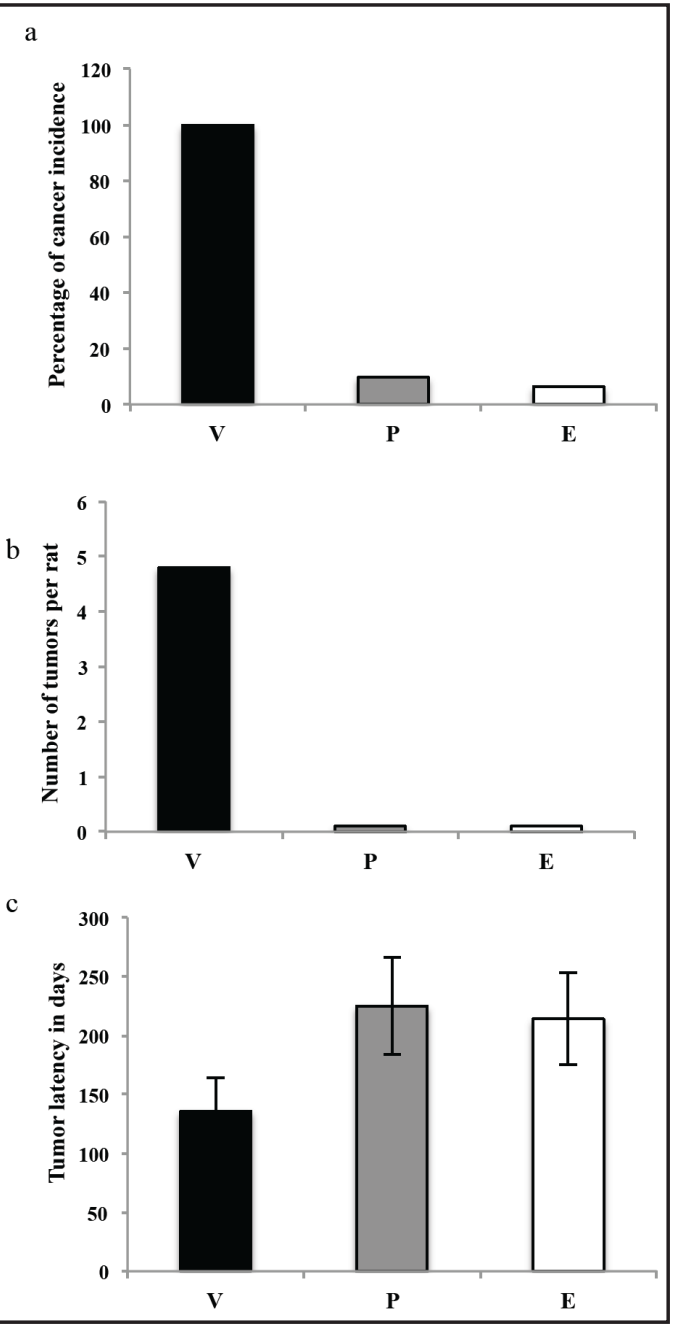

-4.6), Shc1 (-3.1 and -4.1) and Sos1 (-2.4 and -3.9) were down regulated in parous and STET groups (Table 1).

Parity and STET altered the balance between cell proliferation and cell death

From our PCR microarray results, we found, cell proliferation and cell death are the two main mechanisms altered by parity and STET. Cell proliferation and cell death are tightly regulated processes and any deregulation in this leads to increased risk for cancer. Western blot results show that virgin mammary tissues have higher basal level of proliferation and lower apoptotic signaling than that observed in parity and STET, which is in correlation with our gene expression data. A remarkable reduction in the AKT, mTOR, p70S6K and ERK1/2 phosphorylation in parous and STET shows that the overall basal level of proliferation was reduced in these groups (Fig. 2a). Induction of apoptosis, as assessed by the expression of apoptotic markers BCL2, BAX and cleaved Caspase 3 levels, indicated that parous and STET animals had a higher rate of apoptosis compared to controls (Fig. 2b). Parity had significant impact in reducing anti-apoptotic protein BCL2 but STET treatment-induced apoptosis, mainly by increasing pro-apoptotic protein BAX (Fig. 2b). Both parity and STET markedly elevated cleaved caspase 3. Activation of JNK and p38, members of mitogen-activated protein kinases, which are known to play a role in induction of apoptosis, were up regulated in STET (Fig. 2b). Parity increased the phosphorylation of JNK but not p38 when compared to virgin tissues (Fig. 2b). This again confirms our gene expression data showing cumulative reduction in the basal proliferative signaling and an increase in apoptotic signaling in parous and STET groups. 
Table 1. Gene expression analysis by PCR array in normal mammary glands from age matched virgin, parous and STET animals. Parity and STET altered the expression of genes regulating cell survival, apoptosis, cell migration and growth factor signaling. Experiments were performed in triplicates and values represent fold expression (mean \pm SD). All the differentially regulated genes are statistically different from control $(\mathrm{P}<0.05)$

\begin{tabular}{|c|c|c|}
\hline Genes (mRNA) & $\begin{array}{l}\text { Parous } \\
\text { Fold change } \pm \text { SD }\end{array}$ & $\begin{array}{c}\text { STET } \\
\text { Fold change } \pm \text { SD }\end{array}$ \\
\hline \multicolumn{3}{|l|}{ Cell survival } \\
\hline Akt1 & $-5.73 \pm 1.10$ & $-7.7 \pm 2.30$ \\
\hline Pik3ca & $-5.73 \pm 0.93$ & $-6.4 \pm 1.13$ \\
\hline Fkbp1a & $3.01 \pm 0.88$ & $5.9 \pm 0.95$ \\
\hline Eif4B & $-16.87 \pm 2.70$ & $-4.5 \pm 0.64$ \\
\hline Eif4ebp1 & $-8.58 \pm 0.94$ & $3.2 \pm 0.48$ \\
\hline Jun & $-2.67 \pm 0.41$ & $-5.5 \pm 0.82$ \\
\hline Kcnh8 (Elk1) & $-5.73 \pm 0.71$ & - \\
\hline Srf & $-10.11 \pm 1.60$ & $-8.6 \pm 2.71$ \\
\hline Gsk3b & $-5.73 \pm 1.63$ & $-9.9 \pm 2.46$ \\
\hline Foxg1 & $-10.11 \pm 1.18$ & $-7.3 \pm 1.85$ \\
\hline Raf & $-6.65 \pm 0.92$ & $-5.2 \pm 1.04$ \\
\hline \multicolumn{3}{|l|}{ Apoptosis } \\
\hline Casp9 & $1.72 \pm 0.33$ & $4.8 \pm 1.11$ \\
\hline Tlr4 & $-5.73 \pm 0.31$ & $-3.5 \pm 1.02$ \\
\hline Foxo3 & $6.39 \pm 1.25$ & $4.8 \pm 0.89$ \\
\hline Mtcp1 & $-2.72 \pm 0.73$ & $-3.8 \pm 0.77$ \\
\hline Myd88 & $-3.84 \pm 0.51$ & $-4.5 \pm 1.08$ \\
\hline Tcl1a & $-3.73 \pm 0.64$ & $-6.8 \pm 1.65$ \\
\hline \multicolumn{3}{|l|}{ Cell migration } \\
\hline Cdc42 & $-12.87 \pm 1.94$ & $-5 \pm 0.95$ \\
\hline Pak1 & $-1.46 \pm 0.43$ & $-4.3 \pm 0.86$ \\
\hline Rhoa & $-14.95 \pm 1.71$ & $-7.5 \pm 1.98$ \\
\hline Hras & $-5.73 \pm 0.31$ & $-7.9 \pm 1.63$ \\
\hline Ilk & $-2.75 \pm 0.90$ & $-2.2 \pm 0.41$ \\
\hline Itgb4 & $-5.73 \pm 1.98$ & $-9.5 \pm 2.21$ \\
\hline Irak1 & $-9.73 \pm 0.72$ & $-8.8 \pm 1.05$ \\
\hline \multicolumn{3}{|c|}{ Growth factor signaling } \\
\hline Igf1r & $-7.59 \pm 1.53$ & $-6.8 \pm 2.01$ \\
\hline Irs1 & $-4.28 \pm 1.13$ & $-5.3 \pm 1.32$ \\
\hline Grb2 & $-6.16 \pm 0.93$ & $-8.6 \pm 1.99$ \\
\hline Grb10 & $-5.19 \pm 0.75$ & $-4.6 \pm 0.68$ \\
\hline Shc1 & $-3.09 \pm 0.79$ & $-4.1 \pm 0.75$ \\
\hline Sos1 & $-2.39 \pm 0.26$ & $-3.9 \pm 0.64$ \\
\hline
\end{tabular}

Parity and STET influenced the extracellular matrix environment

Mammary epithelial cells have been shown to be influenced by extra cellular matrix proteins in both normal mammary gland development and tumorigenesis [23]. In our investigation, we observed elevated levels of integrin $\beta 4$ in control rat mammary glands but reduced in the parous and STET groups (Fig. 3a). The major signaling pathway, which induces cell proliferation in response to integrin signaling, is focal adhesion kinase and integrin-linked kinase signaling. In our results these signaling molecules showed reduction in their activation status in the parous and STET groups compared to virgin controls (Fig. 3a). Further, we wanted to examine the major factors involved in the epithelial to mesenchymal transition (EMT) process. Among the EMT factors, virgin mammary gland showed increased expression of zeb1 and vimentin reflecting the susceptible nature of the cells to undergo EMT and migration (Fig. 3b), whereas distinct reduction in the expression of the same proteins in the mammary glands of experimental groups showed resistance to EMT and migration conferred by parity and STET. Moreover, the expression levels of $\beta$-catenin and slug were highly reduced in the STET along with increase in E-cadherin levels, an epithelial phenotype marker (Fig. 3b).

Parity and STET reduced the growth factor receptor and hormone receptor signaling

As per our PCR array data and previously published results, the gene expression of growth factor associated signaling and hormone receptor signaling in the mammary gland are down regulated by parity and STET [24]. We investigated whether the gene expression results are influencing the protective nature by affecting at both the translational and post translational levels. Our results revealed that estrogen receptor $\alpha(E R \alpha)$, progesterone receptor (PR) and growth hormone receptor (GHR) were down regulated in the parous and STET mammary 
$\mathbf{a}$

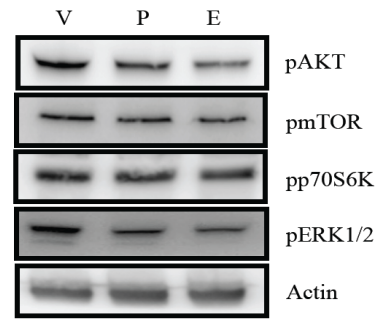

b

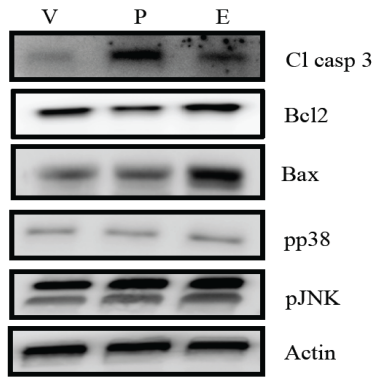

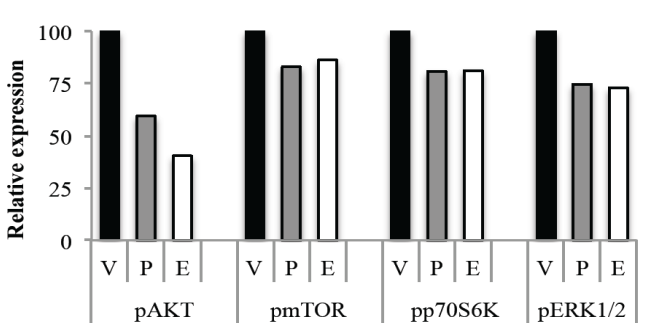

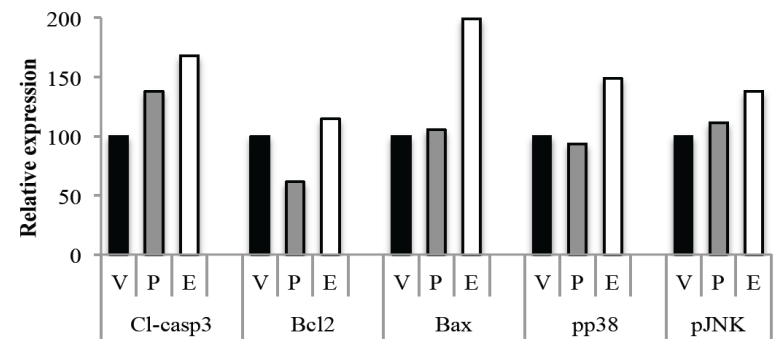

Fig. 2. Cell survival and cell death pathway regulatory proteins were altered by parity and STET favoring a decrease in tumor-promoting microenvironment. a) Immunoblot of pAKT, pmTOR, pp70S6K and pERK1/2 was performed on mammary gland samples and representative images are presented. Major cell proliferative signaling proteins were decreased in the mammary gland of parous and STET rats. b) Representative images of immunoblots showing the levels of cleaved caspase 3, BCL2, BAX, pp38 and pJNK in the mammary gland of control, parous and STET groups. Pro-apoptotic proteins cleaved caspase 3 and BAX are increased in STET group along with pp38 and pJNK. Parous mammary gland samples show a reduction in anti-apoptotic protein BCL2 and increase in cleaved caspase 3 levels along with pp38.

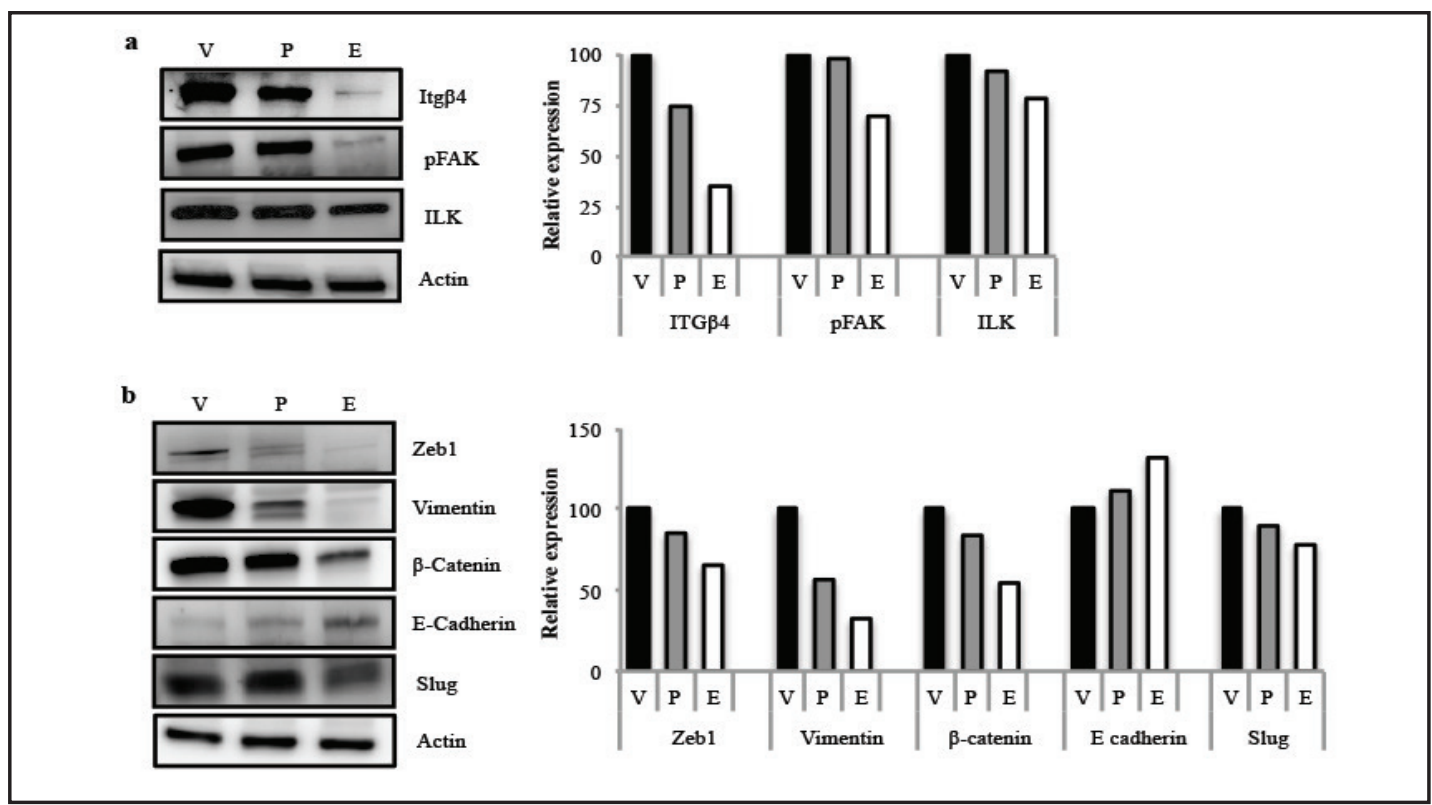

Fig. 3. Extracellular matrix signaling proteins and epithelial-to-mesenchymal transition (EMT) markers were down regulated by parity and STET. a) Levels of Itg $\beta 4$, pFAK and ILK, involved in extra cellular matrix signaling were assessed by immuno blot. b) Western blot of EMT markers Zeb1, Vimentin, $\beta$-catenin, E-cadherin and Slug shows that protein levels of mesenchymal markers has been reduced remarkably in the experimental groups compared to controls. Parity and STET treatment increased the levels of epithelial marker E-cadherin. 


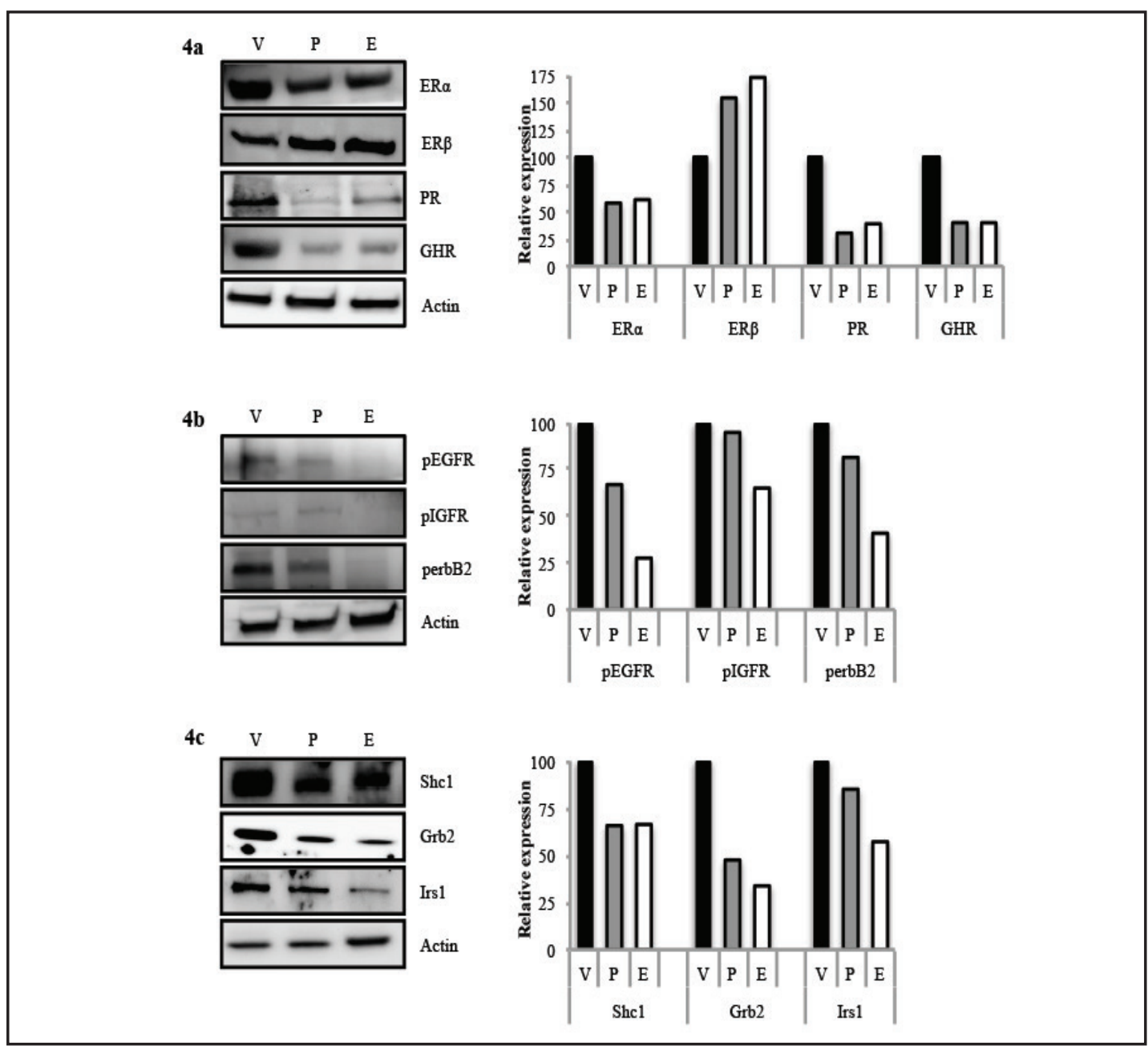

Fig. 4. Parity and STET reduced the growth factor receptor and hormone receptor expression and signaling. a) Expression of mammary tissue levels of $\mathrm{ER} \alpha, \mathrm{ER} \beta$, PR and GHR were assessed using immonoblot analysis. b) Evaluation of phosphorylated forms of growth factor receptors; IGFR, EGFR and erbB2 by Western blot revealed that the basal level of activation of these receptors was decreased in the parous and STET mammary glands. c) Growth factor receptor adaptor proteins, Shc1, Grb2 and Irs1 levels were also analyzed using Western blot.

glands compared to control virgin mammary glands (Fig. 4a). Immunohistochemistry of the mammary gland revealed higher and intense staining of ER $\alpha$ and PR in the virgin controls compared with parous and STET groups (Fig. 5a). In contrast, the level of ER $\beta$ positivity was increased in the experimental groups than that of control (Fig. 5a), which is in agreement with our western blot results. Expression of GHR, EGFR, and IGFR1 in the control mammary gland was higher than those observed in the parous and STET mammary glands. (Fig.4a,b \& 5b). Immunoblot analysis demonstrated that phosphorylation of EGFR, IGFR and erbB2 were also low in the parous and STET animals (Fig 4b). Analysis of downstream signaling of these hormone and growth factors such as Shc1, Grb2 and Irs1 showed a large reduction in the parous and STET mammary glands (Fig. 4c) demonstrating that the genomic alterations are also observed both at the translation and post translational levels.

Parity and STET suppresses JAK/STAT signaling

Growth hormone and growth factor receptors preferentially increase the activation of JAK/STAT pathway [25]. Our results demonstrate that JAK/STAT signaling was down regulated by parity and STET. The level of JAK2 was drastically reduced in the parous and 


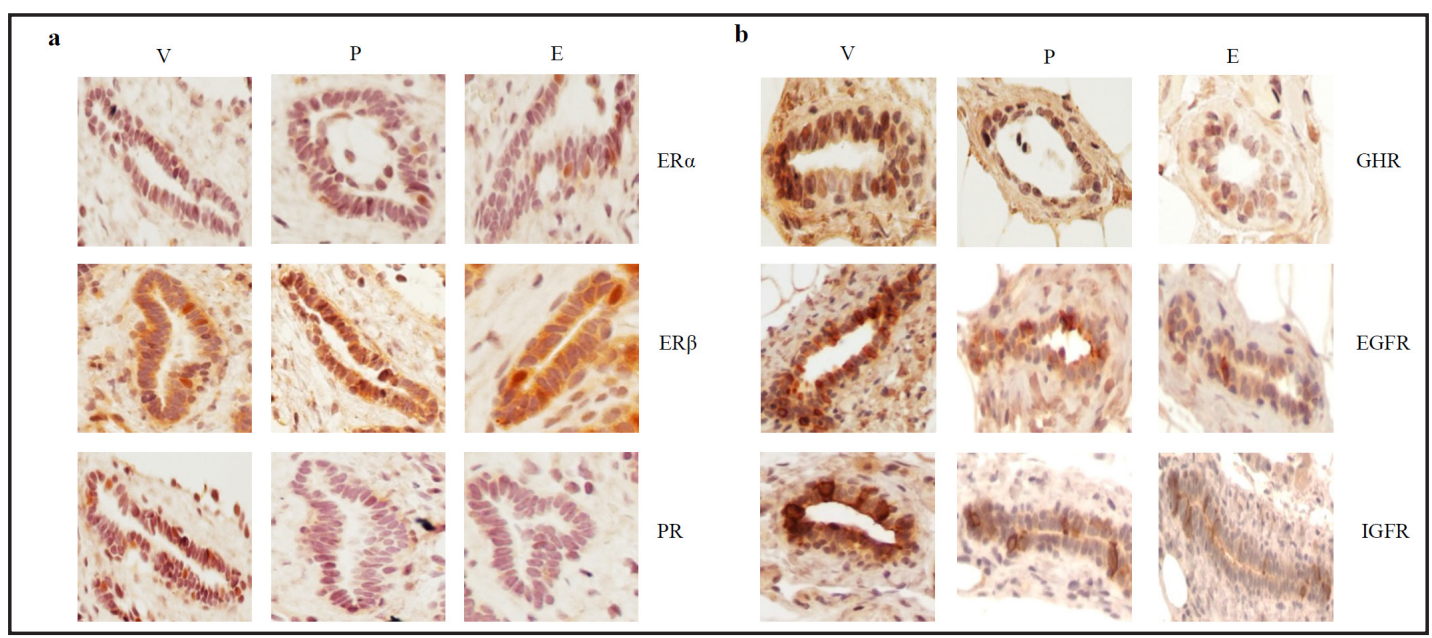

Fig. 5. Immunohistochemical examination of hormone receptors and growth factor receptor shows that parous and STET mammary glands have reduced expression of these receptors. a) Strong staining for ER $\alpha$ and PR were observed in the control mammary glandscompared to the parous and STET mammary glands. ER $\beta$ expression was increased in the experimental groups depicted by intense staining when compared to control mammary glands. b) The number of positive cells and the intensity of staining for GHR, EGFR and IGFR were lower in parous and STET mammary tissues compared to controls.

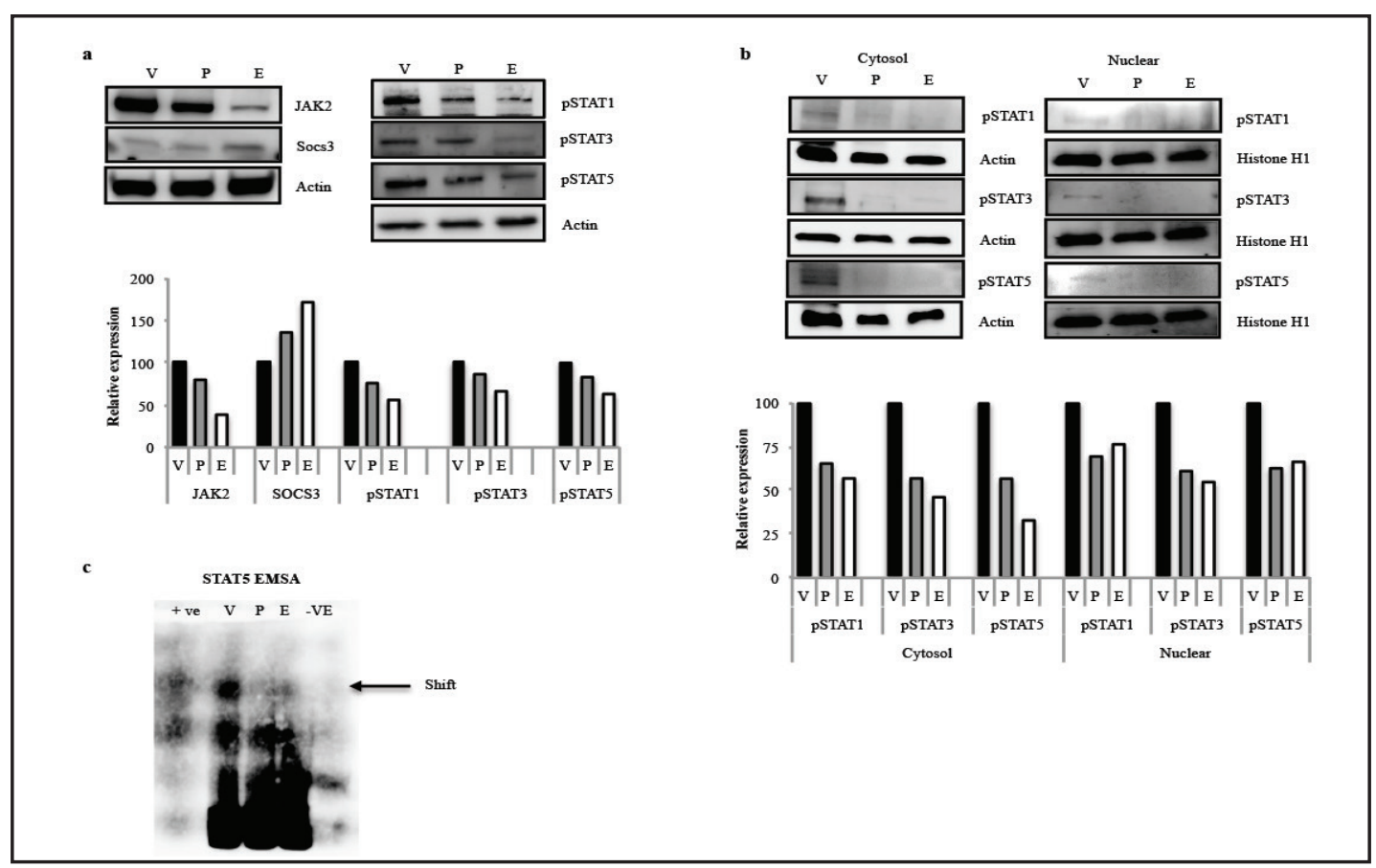

Fig. 6. JAK/STAT pathway was inhibited in parous and STET mammary glands. a) JAK2/STAT pathway components and inhibitor of JAK2/STAT pathway, Socs3 were analyzed using Western blot on total cell lysate of mammary glands. Total JAK2 levels were highly reduced in the STET and parous rats compared to control rats. Downstream effectors of JAK2; STAT 1, 3 and 5 levels were also decreased in the experimental groups. Whereas JAK2/STAT3 signaling inhibitor Socs3 increased in parous and STET groups. b) Western blot analysis of nuclear and cytosolic fraction of the mammary gland samples reveled that both cytosolic and nuclear localization of STAT 1, 3 and 5 were reduced in the experimental groups than controls. c) EMSA analysis of nuclear extracts from the control and experimental group animals showed that STAT5 DNA binding activity was clearly reduced in parous and STET mammary glands. 
STET mammary tissues along with reduction in the activation of downstream signaling molecules, STAT1, STAT3 and STAT5 (Fig. 6a). Further analysis showed that activated STATs 1,3 and 5 levels were found significantly low in the nuclear compartments of parous and STET mammary tissues than that of virgin (Fig. $6 \mathrm{~b} \& \mathrm{c}$ ). The cytosolic fraction also showed reduction in the STAT levels in the experimental groups than in the control virgin rats (Fig. $6 \mathrm{~b})$. These results collectively emphasize that both expression and activation of JAK/STAT pathway proteins were reduced in the parous and STET mammary glands.

\section{Discussion}

Despite several studies investigating the mechanism of parity-induced reduction in breast cancer risk, our current knowledge is very limited. Earlier studies have shown that the cellular, molecular, genomic, systemic and stem cell alterations could be involved in the protective nature of pregnancy and hormonal treatments [6, 10, 24, 26, 27]. One of the main aims of this study is to identify the molecular alterations in the mammary gland in response to pregnancy and short-term treatment with pregnancy levels of estradiol in parallel.

Our in vivo results confirm the protective effects of parity and STET. Mammary cancer incidence was extremely low in parous and STET rats. Multiplicity of mammary tumors was also effectively decreased in parous and STET rats, while latency of mammary tumor development was increased in these groups compared to the controls. All these in vivo studies demonstrate once again the protective nature of parity and STET against mammary carcinogenesis.

Our current study also shows that both parous and STET rats differentially regulate gene expressions. Chromatin modifications including acetylation and methylation have been postulated as one of the mechanisms of gene regulation by parity and estrogen [28, 29]. Pathway focused analysis in the current study and previous transcriptomic analysis revealed several common pathways were similarly regulated in human and rat models such as growth factor receptor signaling, cell proliferation, cell adhesion and apoptosis $[19,24$, 29]. Recent finding suggests that pregnancy induces a change in chromatin remodeling and leaves the chromatin as transcriptionally inactive [30]. Previously, exogenous administration of estradiol has been shown to increase the expression of ER $\beta$ levels in the mammary epithelial cells while reducing the expression of ER $\alpha$. It has been further demonstrated that estradiol increased the expression of histone deacetylase1, which was also accompanied by increased lysine methylation and acetylation of histone $\mathrm{H} 3$ and $\mathrm{H} 4$ respectively [31]. Since, the modification of histones play major role in determining the chromatin structure, we speculate that STET could modify the chromatin structure by altering the histone acetylation and methylation process.

The altered gene regulation of gene expression by parity and STET could be due to the modification of chromatin structure. Further studies are needed in this line to delineate the mechanism of STET in regulating chromatin structure.

Diminished expression of cell survival markers and cell migratory markers could be due to the suppression of ER $\alpha$ and other growth factor receptor pathways. Asztalos et al. showed that pregnancy caused reduction in ER $\alpha$ and ErbB2 levels which is in accordance with our results [32]. It is well recognized that Egfr, Igfr and ErbB2 favors migration and invasion leading to metastasis of breast cancer cells [33]. Down regulation of genes involved in ECM regulation and migration could be due to reduced growth factor receptor signaling. Many reports have shown that ER $\alpha$ can collaborate with growth factor receptors such as Igfr, Egfr and ErbB2 to induce mitogenic signals [34, 35]. Lowered expression of ER $\alpha$ and growth factor receptors induced by parity and STET may be linked to the protective effect. Moreover, parity and STET reduced the activation of AKT and mTOR proteins, which are the major proliferative signaling molecules in a cancer cell. Preclinical data suggests that activation of Akt is mainly regulated by PI3 kinase pathway, a major contributor for breast cancer development [36]. 
Growth factor receptors such as Egfr, Igfr and Erbb2 are the main players that activate PI3 kinase [37, 38]. From our results it is clear that reduction in EGFR, IGFR and ERBB2 activation might have caused reduction in PI3 kinase signaling that in turn resulted in down regulation of phosphorylated AKT and cell proliferation. Another mechanism of regulation of PI3K-AKT-mTOR axis is direct binding and activation of ER $\alpha$ to PI3K which leads to the activation of axis. P70S6K can phosphorylate ER $\alpha$ at serine 167, which increases both its ligand dependent and independent transcriptional activity [39]. A reduction in ER $\alpha$ levels caused by parity and STET could lead to drastic inhibition of PI3K-AKT-mTOR axis, which is a main cell proliferative mechanism utilized by transformed cells. Thrane et al., (2013) demonstrated that the growth factor receptors like HER2, HER3 and EGFR initiates ERK 1/2 [40]. Down regulation of ERK1/2 signaling observed in our studies could be due to reduced activation of growth factor receptor associated tyrosine kinases such as EGFR, IGFR and ERBB2 in parous and STET animals. Suppression of ER $\alpha$ and growth factor receptors in the experimental groups could have contributed to the overall reduction of PI3 kinase, Akt and mTOR pathways, and suppressed tumorigenic environment.

The tumor microenvironment including the extracellular matrix (ECM) and associated stroma, are critical in tumor promotion and progression [41]. ECM and stromal compartments constantly interact with and influence epithelial cell function. Tumors with high expression of integrins increase the risk of recurrence and poor response to therapies emphasizes the importance of integrins in tumor promotion [42]. Integrins, particularly, $\alpha 6 \beta 4$, regulates mammary epithelial cell proliferation and differentiation through Rac activation, leading to subsequent activation of PAK1 or ILK1, which lead to cell survival [43]. Focal adhesion kinase, another dominant downstream target of integrin signaling also plays an important role in mammary gland development and cancer [44]. Activation of FAK, up regulates ERK and STAT5 signaling, results in mammary epithelial cell proliferation [45]. Loss of FAK also correlated with reduced ERK pathway and reduced Stat5 phosphorylation [45]. Moreover, FAK contributes for erbB2 mediated mammary carcinogenesis in mice, showing that FAK is an important mediator in mammary cancer progression in response to various growth factor and ECM stimulation [46]. Parity and STET induced inhibition of integrin and FAK signaling could have partially contributed the blockade in carcinogen induced mammary tumor promotion.

Loss of cell adhesion due to reduced expression of CD44 and E-cadherin is required for EMT and has been frequently reported in progressive breast cancers [47, 48]. EMT has been shown to perturb the balance of epithelial cell specific components thereby plays an essential role in cancer initiation and progression. Transcription factors such as snail, slug, zeb1 and zeb2 induces EMT by inhibiting the epithelial surface protein E cadherin [49-51]. The EMT process also influences apoptosis, cell cycle progression and resistance to therapy [51-54]. Down regulation of zeb1 and slug, well-characterized EMT inducers by parity and STET could be the main reason for increased E-cadherin and restoration of epithelial phenotype. Since, zeb1, $\beta$-catenin and slug pathways are interrelated and well-connected repression of one transcription factor could have strongly influenced the reduction of other transcription factors in the experimental group [49-51]. EGFR signaling ensued by subsequent activation of ERK2 has been shown to reduce the levels of E cadherin through zeb1 pathway [55]. Thomas et al. have shown that ER $\beta$ induces EGFR degradation and thereby inhibits EMT and preserves the epithelial phenotype [56]. In our study, increased expression of ER $\beta$ was found in parous and STET mammary tissues could have caused reduction in EGFR levels and the overall reduction in EMT pathway might have lead to less potential tumorigenic environment and inhibition of tumor progression.

Earlier studies have shown that pregnancy reduces the expression of GHR and its downstream growth factor IGF $[6,10]$. GHR activates JAK/STAT pathway, by inducing dimerization of JAK, which eventually phosphorylate STATs. In the normal mammary gland, JAK2 is predominant and is mainly involved in secretory alveolar cell development $[57,58]$. Several studies have established the pro-tumorigenic roles of GH and IGFs in mammary tumorigenesis [59-61]. In our studies, we also found a reduction in the levels of GHR in 
both parous and STET mammary glands. Felice et al., showed that GH significantly enhances estrogen induced cell proliferation [62]. Our current study also emphasizes that reduction in both GHR and ER $\alpha$ levels could have lead to the reduction of GHR induced JAK2 and IGF signaling.

Phosphorylation of STATs leads to nuclear relocation and binding to their specific downstream promoters, thereby regulating expression. Parity and STET significantly inhibited the activation of STATs and this could be due to suppressed GHR signaling in the mammary glands. Expression of STAT1, 3 and 5 were found in human breast cancers and were positively associated with ER $\alpha$ expression demonstrating interplay between estrogen and GH signaling in breast cancer [63]. Reduced nuclear localization and diminished DNA binding capacity demonstrated by EMSA analysis reveals that STAT induced transcription was blocked in parous and STET mammary glands leading to inhibition of STAT induced oncogenic signaling.

From this study, it is clear that parity and STET induced similar effects on cell survival and apoptosis regulators. The impact of these early changes is subsequently reflected in a large reduction in cancer incidence, tumor latency and multiplicity. Further, this study emphasizes the early change in extra cellular matrix signaling, EMT and downstream effectors of hormonal and growth factor receptors. The early changes induced by pregnancy and STET in the mammary microenvironment are persistent. Moreover cumulative reduction in extracellular signaling pathways like integrin signaling, EMT shows that parity and STET does not support the promotion and progression of mammary lesions formed by carcinogen treatment. Reduced GH and IGF levels leading to reduction in JAK/STAT signaling also contribute to parity and STET induced breast cancer protection. Further study in these lines could lead to the identification of early diagnostic markers for breast cancer in highrisk populations. Detailed studies are required to dissect the mechanism of parity and STET conferred protection against breast cancer.

\section{Acknowledgements}

The financial and material help from the TTUHSC PLFSOM, is greatly appreciated.

\section{Disclosure Statement}

There are no conflicts of interest.

\section{References}

1 MacMahon B, Cole P, Lin TM, Lowe CR, Mirra AP, Ravnihar B, Salber EJ, Valaoras VG, Yuasa S: Age at first birth and breast cancer risk. Bull World Health Organ 1970;43:209-221.

-2 Bain C, Willett W, Rosner B, Speizer FE, Belanger C, Hennekens CH: Early age at first birth and decreased risk of breast cancer. Am J Epidemiol 1981;114:705-709.

-3 Layde PM, Webster LA, Baughman AL, Wingo PA, Rubin GL, Ory HW: The independent associations of parity, age at first full term pregnancy, and duration of breastfeeding with the risk of breast cancer. Cancer and Steroid Hormone Study Group. J Clin Epidemiol 1989;42:963-973.

4 Russo IH, Russo J: Developmental stage of the rat mammary gland as determinant of its susceptibility to 7,12-dimethylbenz[a]anthracene. J Natl Cancer Inst 1978, 61:1439-1449.

5 Nandi S, Guzman RC, Yang J: Hormones and mammary carcinogenesis in mice, rats, and humans: a unifying hypothesis. Proc Natl Acad Sci U S A 1995;92:3650-3657. 
Arumugam et al.: Parity, Estrogen and Breast Cancer

6 Thordarson G, Jin E, Guzman RC, Swanson SM, Nandi S, Talamantes F: Refractoriness to mammary tumorigenesis in parous rats: is it caused by persistent changes in the hormonal environment or permanent biochemical alterations in the mammary epithelia? Carcinogenesis 1995;16:2847-2853. Guzman RC, Yang J, Rajkumar L, Thordarson G, Chen X, Nandi S: Hormonal prevention of breast cancer: mimicking the protective effect of pregnancy. Proc Natl Acad Sci U S A 1999;96:2520-2525.

8 Emerman JT, Leahy M, Gout PW, Bruchovsky N: Elevated growth hormone levels in sera from breast cancer patients. Horm Metab Res 1985;17:421-424.

-9 Thordarson G, Semaan S, Low C, Ochoa D, Leong H, Rajkumar L, Guzman RC, Nandi S, Talamantes F: Mammary tumorigenesis in growth hormone deficient spontaneous dwarf rats; effects of hormonal treatments. Breast Cancer Res Treat 2004;87:277-290.

10 Abrams TJ, Guzman RC, Swanson SM, Thordarson G, Talamantes F, Nandi S: Changes in the parous rat mammary gland environment are involved in parity-associated protection against mammary carcinogenesis. Anticancer Res 1998;18:4115-4121.

11 Henderson BE, Feigelson HS: Hormonal carcinogenesis. Carcinogenesis 2000;21:427-433.

12 Russo J, Tay LK, Russo IH: Differentiation of the mammary gland and susceptibility to carcinogenesis. Breast Cancer Res Treat 1982;2:5-73.

13 Russo J, Russo IH: Biological and molecular bases of mammary carcinogenesis. Lab Invest 1987;57:112137.

14 Smalley M, Ashworth A: Stem cells and breast cancer: A field in transit. Nat Rev Cancer 2003;3:832-844.

15 Huggins C, Moon RC, Morii S: Extinction of experimental mammary cancer. I. Estradiol-17beta and progesterone. Proc Natl Acad Sci U S A 1962;48:379-386.

16 Grubbs CJ, Juliana MM, Whitaker LM: Short-term hormone treatment as a chemopreventive method against mammary cancer initiation in rats. Anticancer Res 1988;8:113-117.

-17 Rajkumar L, Guzman RC, Yang J, Thordarson G, Talamantes F, Nandi S: Short-term exposure to pregnancy levels of estrogen prevents mammary carcinogenesis. Proc Natl Acad Sci U S A 2001;98:11755-11759.

- 18 Rajkumar L, Kittrell FS, Guzman RC, Brown PH, Nandi S, Medina D: Hormone-induced protection of mammary tumorigenesis in genetically engineered mouse models. Breast Cancer Res 2007;9:R12.

19 Blakely CM, Stoddard AJ, Belka GK, Dugan KD, Notarfrancesco KL, Moody SE, D'Cruz CM, Chodosh LA: Hormone-induced protection against mammary tumorigenesis is conserved in multiple rat strains and identifies a core gene expression signature induced by pregnancy. Cancer Res 2006;66:6421-6431.

20 Rajkumar L, Canada A, Esparza D, Collins K, Moreno E, Duong H: Decreasing hormonal promotion is key to breast cancer prevention. Endocrine 2009;35:220-226.

21 Rajkumar L, Arumugam A, Elsayed A, Schecter S, Kotkowski E, Castillo R, de la Torre A, Hernandez C: Longterm hormonal promotion overcomes genetic resistance to mammary cancer. Steroids 2011;76:31-37.

22 Arumugam A, Parada J, Rajkumar L: Mammary cancer promotion by ovarian hormones involves IGFR/ AKT/mTOR signaling. Steroids 2012;77:791-797.

23 Tlsty TD, Hein PW: Know thy neighbor: stromal cells can contribute oncogenic signals. Curr Opin Genet Dev 2001;11:54-59.

24 D'Cruz CM, Moody SE, Master SR, Hartman JL, Keiper EA, Imielinski MB, Cox JD, Wang JY, Ha SI, Keister BA, Chodosh LA: Persistent parity-induced changes in growth factors, TGF-beta3, and differentiation in the rodent mammary gland. Mol Endocrinol 2002;16:2034-2051.

25 Rawlings JS, Rosler KM, Harrison DA: The JAK/STAT signaling pathway. J Cell Sci 2004;117:1281-1283. Medina D: Breast cancer: the protective effect of pregnancy. Clin Cancer Res 2004;10:380S-4S.

Russo J, Moral R, Balogh GA, Mailo D, Russo IH: The protective role of pregnancy in breast cancer. Breast Cancer Res 2005;7:131-142.

28 Leader JE, Wang C, Popov VM, Fu M, Pestell RG: Epigenetics and the estrogen receptor. Ann N Y Acad Sci 2006;1089:73-87.

-29 Peri S, de Cicco RL, Santucci-Pereira J, Slifker M, Ross EA, Russo IH, Russo PA, Arslan AA, Belitskaya-Levy I, Zeleniuch-Jacquotte A, Bordas P, Lenner P, Ahman J, Afanasyeva Y, Johansson R, Sheriff F, Hallmans G, Toniolo P, Russo J: Defining the genomic signature of the parous breast. BMC Med Genomics 2012;5:468794-5-46. 
Arumugam et al.: Parity, Estrogen and Breast Cancer

-30 Russo J, Santucci-Pereira J, de Cicco RL, Sheriff F, Russo PA, Peri S, Slifker M, Ross E, Mello ML, Vidal BC, Belitskaya-Levy I, Arslan A, Zeleniuch-Jacquotte A, Bordas P, Lenner P, Ahman J, Afanasyeva Y, Hallmans G, Toniolo P, Russo IH: Pregnancy-induced chromatin remodeling in the breast of postmenopausal women. Int J Cancer 2012;131:1059-1070.

- 31 Wang H, Zhou C, Chen W, Li T, Huang J, Zhuang G: Supraphysiological estrogen levels adversely impact proliferation and histone modification in human embryonic stem cells: possible implications for controlled ovarian hyperstimulation assisted pregnancy. Eur J Obstet Gynecol Reprod Biol 2011;155:58-64.

-32 Asztalos S, Gann PH, Hayes MK, Nonn L, Beam CA, Dai Y, Wiley EL, Tonetti DA: Gene expression patterns in the human breast after pregnancy. Cancer Prev Res (Phila) 2010;3:301-311.

33 Yang SY, Miah A, Pabari A, Winslet M: Growth Factors and their receptors in cancer metastases. Front Biosci (Landmark Ed) 2011;16:531-538.

34 Gee JM, Robertson JF, Gutteridge E, Ellis IO, Pinder SE, Rubini M, Nicholson RI: Epidermal growth factor receptor/HER2/insulin-like growth factor receptor signalling and oestrogen receptor activity in clinical breast cancer. Endocr Relat Cancer 2005;12:S99-S111.

- 35 Fagan DH, Yee D: Crosstalk between IGF1R and estrogen receptor signaling in breast cancer. J Mammary Gland Biol Neoplasia 2008;13:423-429.

-36 Lauring J, Park BH, Wolff AC: The phosphoinositide-3-kinase-Akt-mTOR pathway as a therapeutic target in breast cancer. J Natl Compr Canc Netw 2013;11:670-678.

- 37 Stoica GE, Franke TF, Moroni M, Mueller S, Morgan E, Iann MC, Winder AD, Reiter R, Wellstein A, Martin MB, Stoica A: Effect of estradiol on estrogen receptor-alpha gene expression and activity can be modulated by the ErbB2/PI 3-K/Akt pathway. Oncogene 2003;22:7998-8011.

-38 Stoica GE, Franke TF, Wellstein A, Czubayko F, List HJ, Reiter R, Morgan E, Martin MB, Stoica A: Estradiol rapidly activates Akt via the ErbB2 signaling pathway. Mol Endocrinol 2003;17:818-830.

-39 Campbell RA, Bhat-Nakshatri P, Patel NM, Constantinidou D, Ali S, Nakshatri H: Phosphatidylinositol 3-kinase/AKT-mediated activation of estrogen receptor alpha: a new model for anti-estrogen resistance. J Biol Chem 2001;276:9817-9824.

40 Thrane S, Lykkesfeldt AE, Larsen MS, Sorensen BS, Yde CW: Estrogen receptor alpha is the major driving factor for growth in tamoxifen-resistant breast cancer and supported by HER/ERK signaling. Breast Cancer Res Treat 2013;139:71-80.

41 Howlett AR, Bissell MJ: The influence of tissue microenvironment (stroma and extracellular matrix) on the development and function of mammary epithelium. Epithelial Cell Biol 1993;2:79-89.

-42 Bergamaschi A, Tagliabue E, Sorlie T, Naume B, Triulzi T, Orlandi R, Russnes HG, Nesland JM, Tammi R, Auvinen P, Kosma VM, Menard S, Borresen-Dale AL: Extracellular matrix signature identifies breast cancer subgroups with different clinical outcome. J Pathol 2008;214:357-367.

43 Friedland JC, Lakins JN, Kazanietz MG, Chernoff J, Boettiger D, Weaver VM: alpha6beta4 integrin activates Rac-dependent p21-activated kinase 1 to drive NF-kappaB-dependent resistance to apoptosis in 3D mammary acini. J Cell Sci 2007;120:3700-3712.

44 Keely PJ: Mechanisms by which the extracellular matrix and integrin signaling act to regulate the switch between tumor suppression and tumor promotion. J Mammary Gland Biol Neoplasia 2011;16:205-219.

45 Nagy T, Wei H, Shen TL, Peng X, Liang CC, Gan B, Guan JL: Mammary epithelial-specific deletion of the focal adhesion kinase gene leads to severe lobulo-alveolar hypoplasia and secretory immaturity of the murine mammary gland. J Biol Chem 2007;282:31766-31776.

46 Lahlou H, Sanguin-Gendreau V, Frame MC, Muller WJ: Focal adhesion kinase contributes to proliferative potential of ErbB2 mammary tumour cells but is dispensable for ErbB2 mammary tumour induction in vivo. Breast Cancer Res 2012;14:R36.

47 Thiery JP: Epithelial-mesenchymal transitions in tumour progression. Nat Rev Cancer 2002;2:442-454.

48 Yori JL, Seachrist DD, Johnson E, Lozada KL, Abdul-Karim FW, Chodosh LA, Schiemann WP, Keri RA: Kruppel-like factor 4 inhibits tumorigenic progression and metastasis in a mouse model of breast cancer. Neoplasia 2011;13:601-610.

-49 Batlle E, Sancho E, Franci C, Dominguez D, Monfar M, Baulida J, Garcia De Herreros A: The transcription factor snail is a repressor of E-cadherin gene expression in epithelial tumour cells. Nat Cell Biol 2000;2:8489. 
-50 Cano A, Perez-Moreno MA, Rodrigo I, Locascio A, Blanco MJ, del Barrio MG, Portillo F, Nieto MA: The transcription factor snail controls epithelial-mesenchymal transitions by repressing E-cadherin expression. Nat Cell Biol 2000;2:76-83.

51 Nieto MA, Cano A: The epithelial-mesenchymal transition under control: global programs to regulate epithelial plasticity. Semin Cancer Biol 2012;22:361-368.

52 Nieto MA: The ins and outs of the epithelial to mesenchymal transition in health and disease. Annu Rev Cell Dev Biol 2011;27:347-376.

-53 Mejlvang J, Kriajevska M, Vandewalle C, Chernova T, Sayan AE, Berx G, Mellon JK, Tulchinsky E: Direct repression of cyclin D1 by SIP1 attenuates cell cycle progression in cells undergoing an epithelial mesenchymal transition. Mol Biol Cell 2007;18:4615-4624.

-54 Ansieau S, Bastid J, Doreau A, Morel AP, Bouchet BP, Thomas C, Fauvet F, Puisieux I, Doglioni C, Piccinin S, Maestro R, Voeltzel T, Selmi A, Valsesia-Wittmann S, Caron de Fromentel C, Puisieux A: Induction of EMT by twist proteins as a collateral effect of tumor-promoting inactivation of premature senescence. Cancer Cell 2008;14:79-89.

55 Shin S, Blenis J: ERK2/Fra1/ZEB pathway induces epithelial-to-mesenchymal transition. Cell Cycle 2010;9:2483-2484.

-56 Thomas C, Rajapaksa G, Nikolos F, Hao R, Katchy A, McCollum CW, Bondesson M, Quinlan P, Thompson A, Krishnamurthy S, Esteva FJ, Gustafsson JA: ERbeta1 represses basal breast cancer epithelial to mesenchymal transition by destabilizing EGFR. Breast Cancer Res 2012;14:R148.

-57 Shillingford JM, Miyoshi K, Robinson GW, Grimm SL, Rosen JM, Neubauer H, Pfeffer K, Hennighausen L: Jak2 is an essential tyrosine kinase involved in pregnancy-mediated development of mammary secretory epithelium. Mol Endocrinol 2002;16:563-570.

-58 Wagner KU, Krempler A, Triplett AA, Qi Y, George NM, Zhu J, Rui H: Impaired alveologenesis and maintenance of secretory mammary epithelial cells in Jak2 conditional knockout mice. Mol Cell Biol 2004;24:5510-5520.

59 Tornell J, Carlsson B, Pohjanen P, Wennbo H, Rymo L, Isaksson O: High frequency of mammary adenocarcinomas in metallothionein promoter-human growth hormone transgenic mice created from two different strains of mice. J Steroid Biochem Mol Biol 1992;43:237-242.

60 Pollak M, Blouin MJ, Zhang JC, Kopchick JJ: Reduced mammary gland carcinogenesis in transgenic mice expressing a growth hormone antagonist. Br J Cancer 2001;85:428-430.

61 Swanson SM, Unterman TG: The growth hormone-deficient Spontaneous Dwarf rat is resistant to chemically induced mammary carcinogenesis. Carcinogenesis 2002;23:977-982.

62 Felice DL, El-Shennawy L, Zhao S, Lantvit DL, Shen Q, Unterman TG, Swanson SM, Frasor J: Growth hormone potentiates 17beta-estradiol-dependent breast cancer cell proliferation independently of IGF-I receptor signaling. Endocrinology 2013;154:3219-3227.

-63 Furth PA: STAT signaling in different breast cancer sub-types. Mol Cell Endocrinol 2014;382:612-615. 